\title{
Analysis of the air temperature and relative humidity measurements in Budapest-Ferencváros
}

\author{
Rita PONGRÁCZ¹, Judit BARTHOLY, Zsuzsanna DEZSŐ and Csenge DIAN
}

\begin{abstract}
Ferencváros ( $9^{\text {th }}$ district of Budapest) is one of the oldest districts among the 23 ones of the Hungarian capital. It is located near the river Danube in the southern central very heterogeneous part of the city, consisting of three- and four-storey old buildings, block houses with 4 or 8 levels, brownfield industrial areas, and large areas occupied by the railways system. Due to the functional and structural changes of special subsections of the district substantial local climatic changes occurred in the past few decades. The local government made efforts to complete several block rehabilitation programs already starting from the 1980s. Within the framework of these programs inner parts of the blocks were demolished, thus, inside the blocks more public green areas could be created. In order to evaluate the climatic conditions, we have recently initiated an in situ urban measurement program in the Inner Ferencváros and the rehabilitation zone. Air temperature and relative humidity where measured along a multi-site measuring path covering the target area, and continuously at a single site representative to the rehabilitation zone. Our measurements are compared to the regular meteorological data available from the Budapest-Pestszentlörinc synoptic station. Our preliminary results are presented in this paper, which highlights the general characteristics of the urban environmental effects.
\end{abstract}

Keywords: block rehabilitation, in situ measurements, urban heat island, dew point temperature

\section{Introduction}

Concentrated human presence and the associated anthropogenic activities modify the natural environment in various ways. This cause several environmental and socio-economic issues, which should especially be assessed in large urban areas. Since more than half of the global population (and about $70 \%$ of the Hungarian population) is living in cities (United Nations, 2012; KSH 2012) these issues affect many people all over the world as well, as in Hungary. The artificial surface cover modifies the radiation budget resulting in higher urban temperature compared to the surrounding rural vicinity. Furthermore, the hydrological cycle is also modified in the urban environment through the lack of natural soil cover, which would serve as additional source of atmospheric humidity.
The complex environmental effect can be summarized as the urban heat island (UHI), which is usually characterized by the intensity, i.e., the temperature difference between the urban area and the rural surroundings. One approach to study the urban temperature surplus uses air temperature measured at regular meteorological stations or moving vehicles for the analysis of UHI (e.g. OKe, T.R. 1973; UnGER, J. et al. 2000), whereas another approach applies surface temperature from satellite or aircraft measurements to analyse the surface UHI (e.g. PRICE, J.C. 1979; Pongrácz, R. et al. 2006; Ben-Dor, E. and SAARoni, H. 1997). Within the framework of the urban climate research at the Department of Meteorology of the Eötvös Loránd University surface UHI effects of several Hungarian and Central European cities have been analysed using remotely sensed

\footnotetext{
${ }^{1}$ Department of Meteorology, Eötvös Loránd University, H-1117 Budapest, Pázmány Péter sétány 1/a. E-mails: prita@nimbus.elte.hu, bartholy@caesar.elte.hu, dezsozsuzsi@caesar.elte.hu, diancsenge@gmail.com
} 
surface temperature (Dezsô, Zs. et al. 2005, Pongrácz, R. et al. 2010, 2015).

In order to extend our research focus we have initiated a new ground-based measurement program in Budapest at a smaller spatial scale. To cover the entire 525 $\mathrm{km}^{2}$ area of the capital city is too ambitious at this point, as a first step we started with one of the 23 districts. The selection of the target district was made according to several aspects: (i) the UHI impacts are significant, (ii) the area is heterogeneous, and (iii) the local government is interested in and willing to build a long-term research cooperation. Among the candidate districts, Ferencváros (the $9^{\text {th }}$ district of Budapest) was finally selected due to the multi-decadal-long block rehabilitation programs supported by the local government.

The total population of Ferencváros is currently about 60,000 (Budapest Capital Local Government, 2011), and the spatial extension is $12.5 \mathrm{~km}^{2}$, which indicate that this is a medium-size district. It is located at the eastern side along the river Danube, which divides the entire city and the downtown region into two parts. Ferencváros itself is a very heterogeneous part of the city with cultural centres, offices, residential, and industrial areas. The district consists of three- and four-storey old buildings, block houses with 4 or 8 levels, brown industrial areas, and large areas occupied by the railways system. The most inner city part is the Inner Ferencváros (Figure 1),

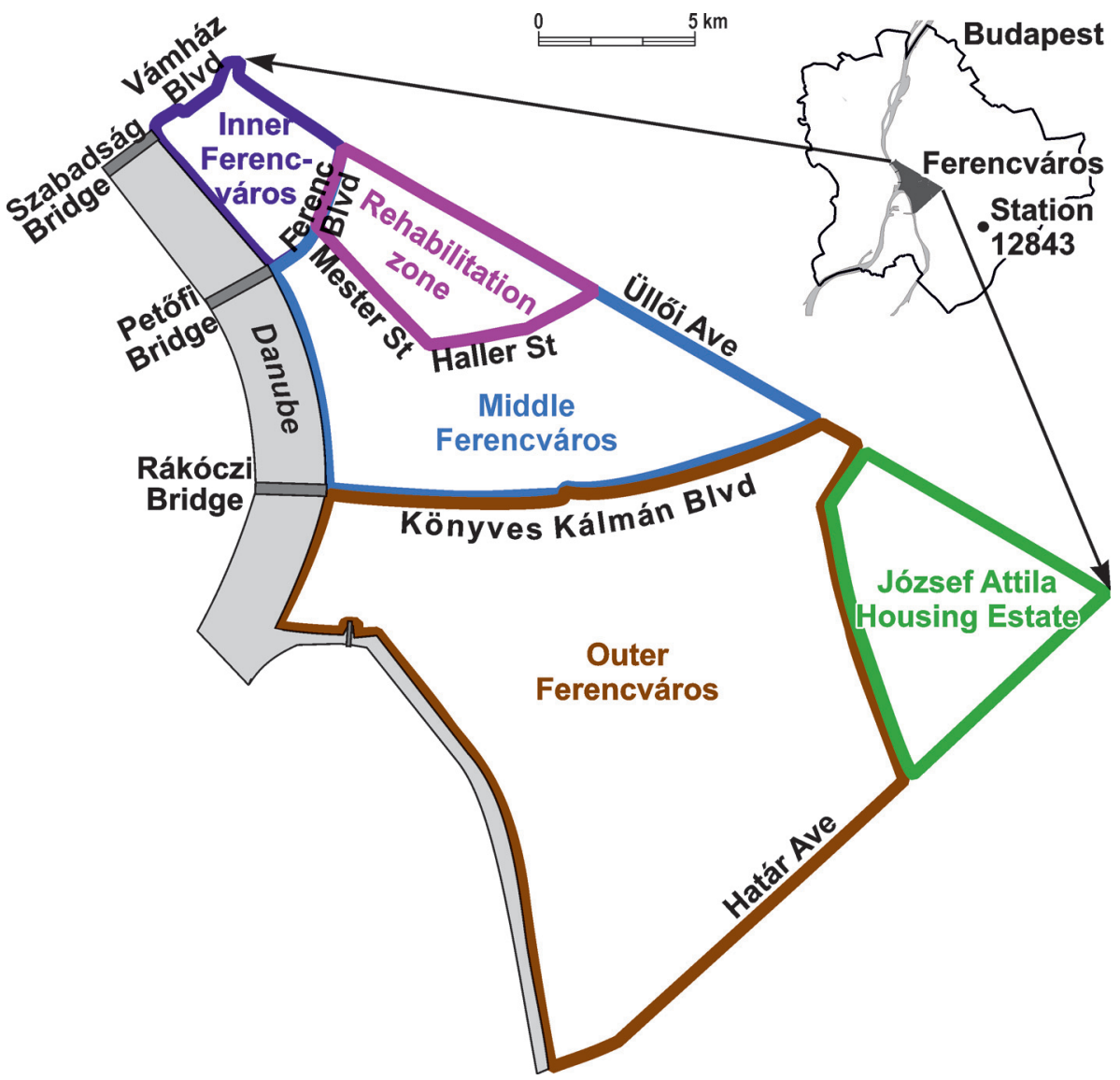

Fig. 1. Location and structure of Ferencváros within Budapest, and location of the reference synoptic station no. 12843 at Pestszentlörinc, south-eastern part of the city 
where mostly offices and multi-residential houses can be found. The past and present (though very decreased) industrial activity is concentrated in the Outer Ferencváros subsection. Residential block houses form the József Attila housing estate, which became quite friendly and green recently. Although this is one of the oldest housung estate of Budapest built in the 1970s, however, the trees planted several decades ago have grown and provide nice environmental conditions to this part of the district.

Partly due to the functional and structural changes of special subsections of the district substantial local climatic changes occurred in the past few decades. The local government made concentrated efforts to improve the environment for the citizens starting from the 1980s. Since 1993 in the most densely built inner part of the district (Inner and Central Ferencváros) entire blocks were renovated and modified. Within the framework of block rehabilitation programs inner parts of the blocks were demolished, thus, inside the renewed blocks more common green spaces could be created. Moreover, several parks have been enlarged, and small green areas have been created along the streets (Local Government of Ferencváros, 2010). The overall increase both in terms of number and spatial extension of green areas is illustrated in Figure 2.
In order to describe the climatic conditions of the district, with special focus on the rehabilitation zone, in situ measurement program has been introduced. This program consists of two types of measurements: (i) series of measurements in several sites along a predefined path, and (ii) continuous measurements at a single site. For comparison, measurements at another site in Budapest (synoptic station no. 12843 at Pestszentlörinc) are used. In this study, details of the measurement program are discussed together with preliminary results for both types of measurements. Then, the main conclusions are summarized at the end of the paper.

\section{Measurements along the predefined measuring path}

In our urban climate measurement program in the rehabilitation zone of Ferencváros, air temperature and relative humidity are recorded with two Voltcraft HT-200 instruments along a predefined path consisting of 22 measuring points (Figure 3, Table 1), which covers the target area.

The measuring sites are selected at different representative points of the district, such as green parks (Photo 1), narrow streets,

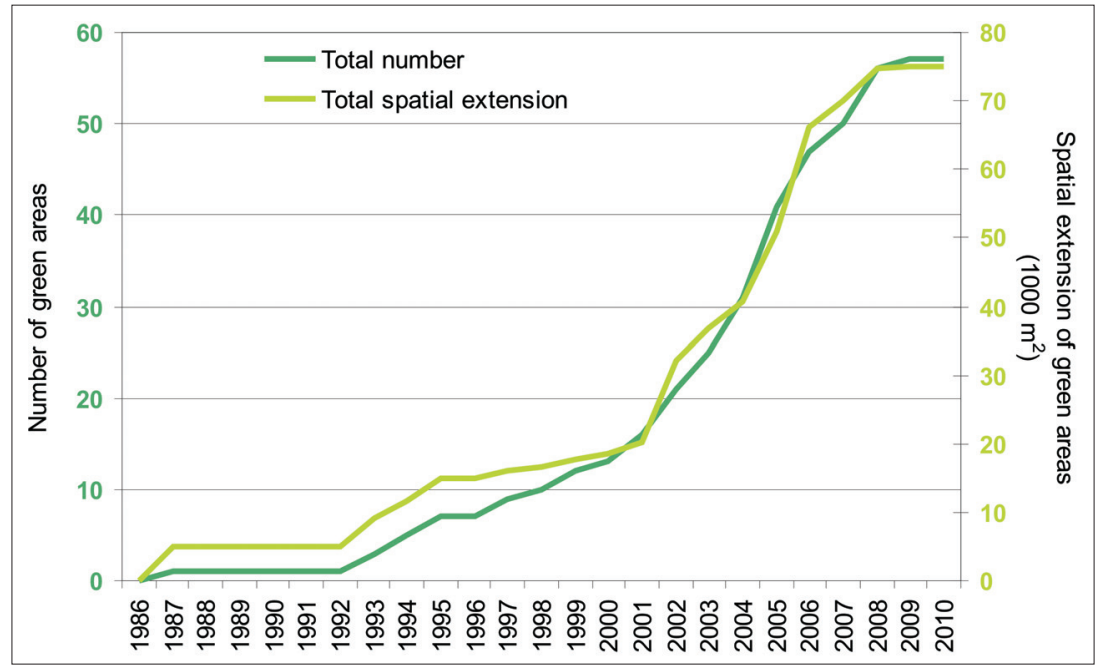

Fig. 2. Increase of the green areas in Budapest-Ferencváros 


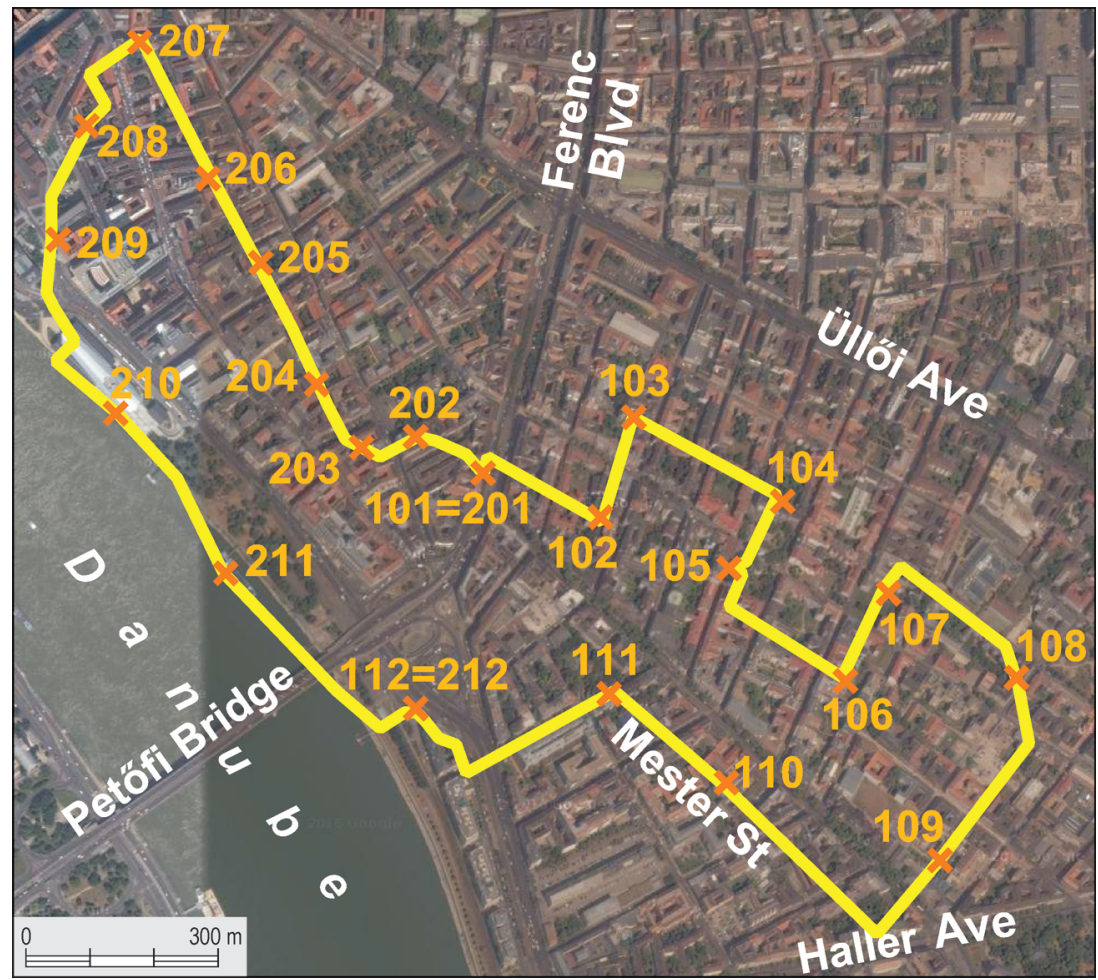

Fig. 3. Measuring points along the predefined path. Locations of measuring sites are listed in Table 1.

Table 1. Location of the measuring sites along the predefined path

\begin{tabular}{|c|c|}
\hline \multicolumn{2}{|c|}{ Site number: location along the } \\
\hline northwestern & southeastern \\
\hline \multicolumn{2}{|c|}{ part of the predefined path } \\
\hline 201: Ferenc bld. / Tompa st. & 101: Ferenc bld. / Tompa st. \\
\hline 202: Bakáts sq. / Tompa st. & 102: Tompa st. / Liliom st. \\
\hline 203: Bakáts sq. / Ráday st. & 103: Liliom st. / Tüzoltó st. \\
\hline 204: Ráday st. 42 & 104: Tüzoltó st. / Bokréta st. \\
\hline 205: Ráday st. / Biblia st. & 105: Ferenc sq. \\
\hline 206: Ráday/Erkel st. & 106: Balázs Béla st. / Thaly Kálmán st. \\
\hline 207: Kálvin sq. & 107: University building (SOTE) \\
\hline 208: Lónyay st. / Gönczy Pál st. & 108: Kerekerdő Park \\
\hline 209: Csarnok sq. & 109: Márton st./ Gát st. \\
\hline 210: Building Bálna & 110: Mester st. /Viola st. \\
\hline 211: Nehru Park & 111: Mester st. / Tinódi st. \\
\hline 212: Boráros sq. & 112: Boráros sq. \\
\hline
\end{tabular}

paved squares and roads (Photo 2). The whole measuring path is divided into two parts, where the measurements are recorded simultaneously: (i) from 101 to 112, and (ii) from 201 to 212 .
The starting and ending sites are identical, i.e. 101 is identical to 201, and 112 is 212. These simultaneous walking tours last about 1-1.5 hours. Then, the measurements are recorded along the same two paths but in 

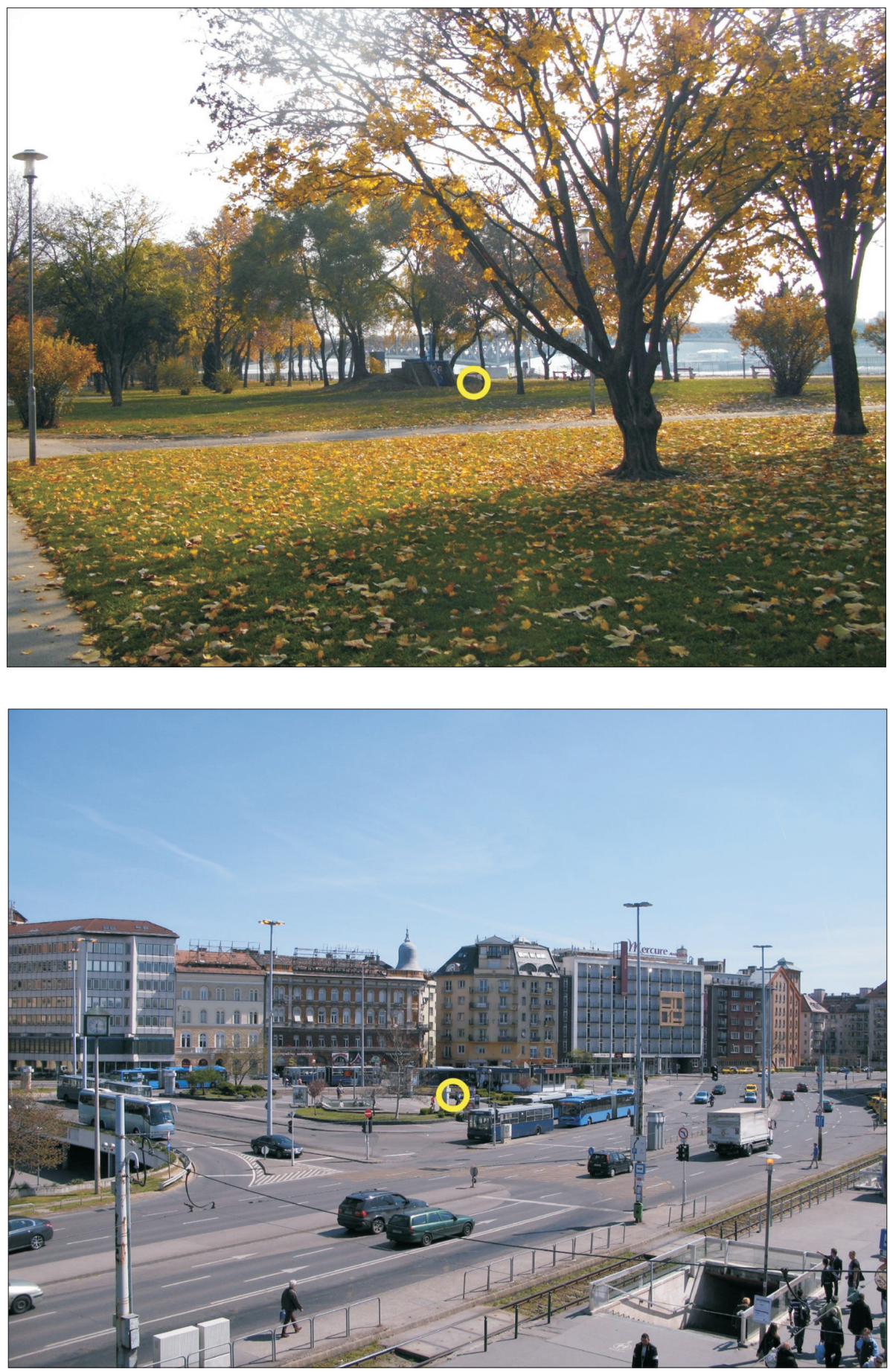

Photo 1 and 2. Measuring sites with completely different surface cover: vegetation cover at Nehru Park (211) (above) and paved cover at Boráros square $(112=212)$ (below). Measuring points are indicated by yellow circles 
reverse order (i.e. starting from 112/212, and ending at 101/201). Evidently, the measurements cannot be recorded at the same time. Therefore, in order to temporally adjust the measurements, two records from the consequent (and reversed) partial paths are averaged over each site.

This procedure results in average values representative for a virtual time along the whole path. More precisely, since the moving speeds between sites and the distances between sites are not perfectly identical, this virtual time is given as a 10-20 minute time period. For calculating the UHI intensity, temperature measurements are compared to the hourly recorded data of the Budapest synoptic station (ID number: 12843) located in the south-eastern suburb district of the city (Pestszentlörinc). Similarly, difference between dew point temperature values derived from relative humidity measurements are calculated and analysed.

The measurement program started in early spring of 2015, the measuring dates are listed in Table 2. The measurements are scheduled once a week (on Friday), from about noon until the late evening. The on going measurement program involves BSc students specialized in Earth sciences and MSc students specialized in meteorology, therefore, 8 dates were completed in the spring semester of 2015, and another 8 dates in the autumn semester of 2015. During the summer three consecutive days were selected for the measurement program in early July, and the last Friday of August. We are planning to extend further the measurement program at the study area and complete several years of measurements, so the seasonal cycle of tem-

Table 2. Measuring dates during 2015

\begin{tabular}{c|l|c}
\hline Spring & Summer & Autumn \\
\hline 20 March & 6 July & 18 September \\
27 March & 7 July & 2 October \\
3 April & 8 July & 9 October \\
10 April & 28 August & 6 November \\
17 April & - & 13 November \\
24 April & - & 20 November \\
8 May & - & 27 November \\
15 May & - & 4 December \\
\hline
\end{tabular}

perature and relative humidity differences can be analysed as well, as the inter-annual variability and changes.

\section{Results from the measurements along the predefined measuring path}

Since UHI together with a heat-wave results in excessive heat stress for humans, and thus, significant health consequences, measurements on one of the heat-wave days (i.e. 7 July) occurred in the summer 2015 are discussed in this paper. The entire heat-wave period in the Carpathian Basin was dominated by a strong anticyclone over Central/ Eastern Europe with clear sky conditions. The averaged air temperature values and the differences compared to the reference station throughout the day - starting from about 14:00 to 21:00 - are shown in Figure 4.

The warmest site was the Boráros square (site no. $112=212$ ), which is a large paved square near the river Danube with main stations of the public transportation system and partially surrounded by four-storey buildings (Photo 2). The recorded temperature exceeded $38^{\circ} \mathrm{C}$ between 14:00 and 16:30. The coolest sites were the greener spaces (i.e. park along the Danube, site no. 211; park in the rehabilitation zone, site no. 105). Towards the evening (starting around 17:30) the cooling rate until the end of the measurements (around 21:00) at all the measuring sites was about $1.5-2.0^{\circ} \mathrm{C} / \mathrm{h}$. However, the air temperature remained above $30^{\circ} \mathrm{C}$. As far as the UHI intensity, the largest values occurred at the largely paved Boráros square $(112=212)$. The largest temperature difference between our measurements and the reference station exceeded $4{ }^{\circ} \mathrm{C}$.

Similarly to the air temperature, the results of the dew point temperature are shown in Figure 5. Dew point temperature values recorded in the afternoon were generally lower than dew point temperature in the evening. The difference relative to the synoptic station decreased from about $3-5^{\circ} \mathrm{C}$ (at about 14:00) to about $1-2{ }^{\circ} \mathrm{C}$ (by about $21: 00$ ). 

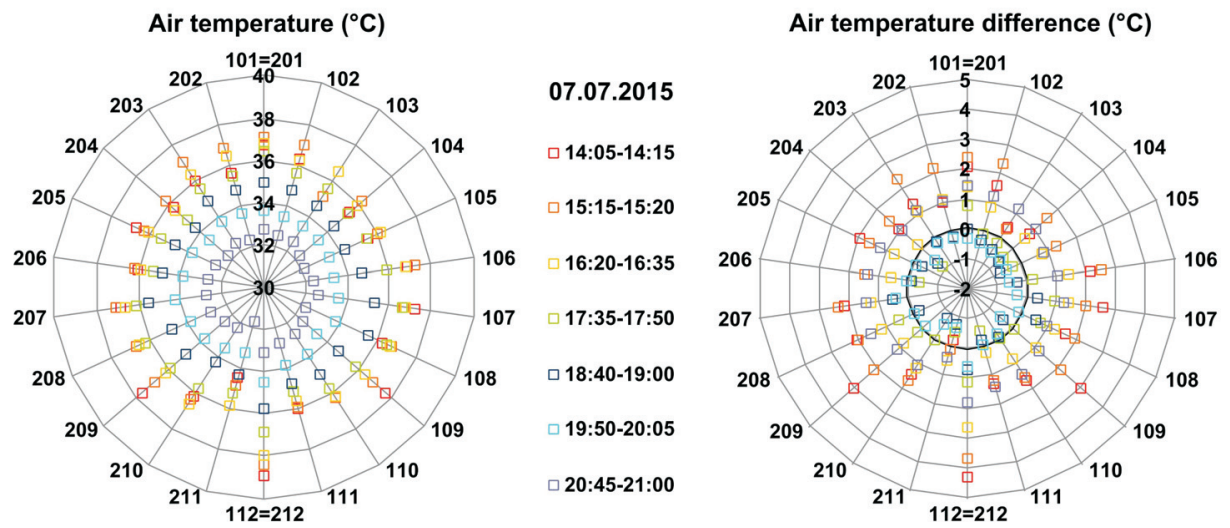

Fig. 4. Averaged temperature and UHI intensity values along the measuring path during the 7 measuring periods, 7 July 2015
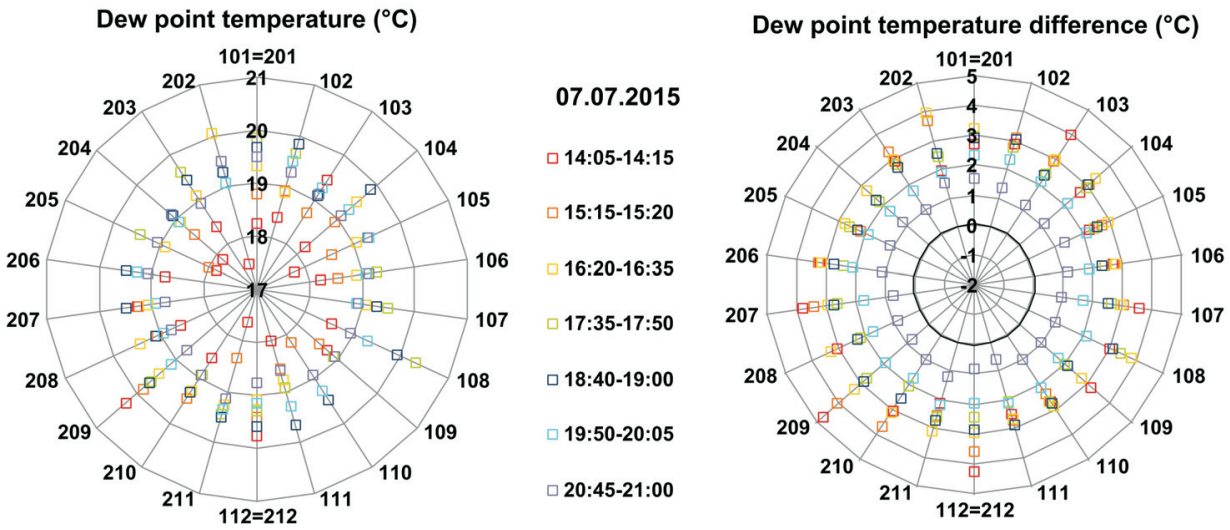

Fig. 5. Averaged dew point temperature values and the difference from the Budapest-Pestszentlörinc synoptic station along the measuring path during the 7 measuring periods, 7 July 2015

In order to visualise the relationship between the air temperature and dew point temperature differences, the values for the individual sites shown in Figures 4 and 5 are averaged and plotted in Figure 6. It can be clearly seen that the UHI intensity values between 17:30 and 20:00 were quite low, close to zero. This implies that the suburban temperature and the inner-city temperature did not differ significantly in the late afternoon before sunset. Since the last measuring period was already after the sunset (at 20:44), the well-known increase of UHI intensity after the evening (e.g. Оке, T.R. 1982) was clearly detected in our measurements.

The detected higher UHI intensity values in the afternoon period are probably associated with the faster temperature increase of the target urban area compared to the suburban reference station, which is later compensated by the temperature change in the suburban area becoming more similar to the more densely built-up part of the city. Then, in the evening around sunset the suburban area cooled down faster, and the second maximum occurred. Similar results were shown 


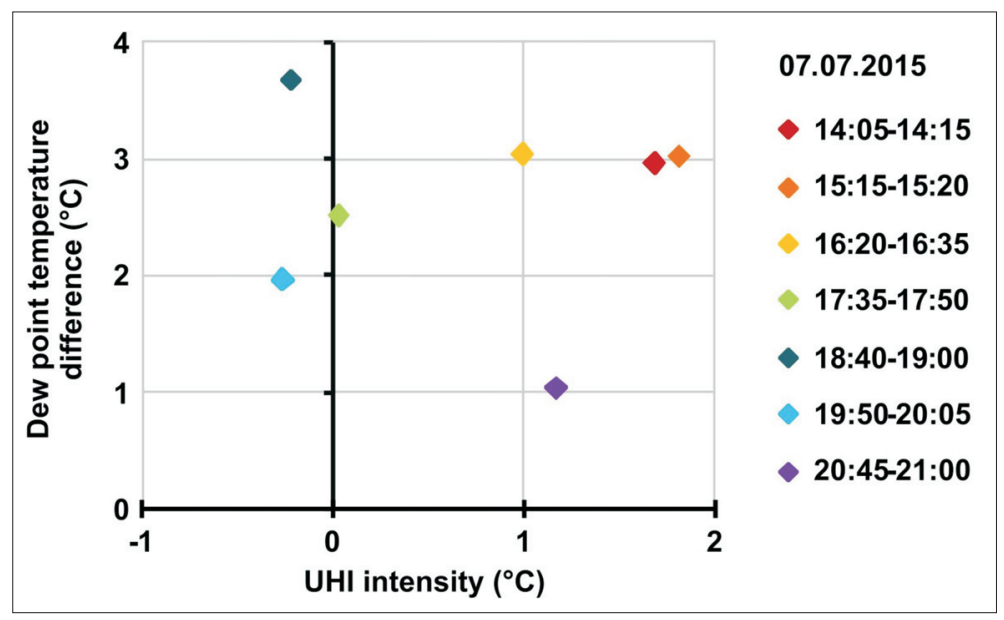

Fig. 6. Relationship between the averaged UHI intensity values and dew point temperature differences relative to Budapest-Pestszentlörinc synoptic station data during the 7 measuring periods, 7 July 2015 (sunset occurred at 20:44)

for the Polish city Poznań (Pó£rolniczak, M. et al. 2015). However, in order to fully justify the above explanation, longer measurements are needed in Budapest as well, possibly throughout entire 24-hour periods. This is why we are planning to extend our measuring period.

\section{Continuous measurements at a single site}

In addition to the moving measurements, air temperature and relative humidity values have been recorded at a permanent site, which is one of the measuring sites along the predefined path, no. 105 located at the Ferenc square (Photo 3 ).

This location has been selected due to its central location within the rehabilitation zone of the district and, moreover, it can be considered as a representative site to the results of the rehabilitation process. The square is surrounded by 4-level houses, and it is covered mainly by vegetation with some paved footpaths for pedestrians. The investigated vegetation consists of several deciduous trees and bushes, and grass can be found on the ground.
For the air temperature measurements Voltcraft DL-141TH is used with 10 minutes recording intervals starting around midday until the evening on the days listed in Table 2. These measurements are compared to the regular meteorological measurements recorded at the Budapest synoptic station located at the south-eastern part of the city as a reference (see Figure 1).

\section{Results from the measurements at Ferenc square}

Among the completed 20 days of our measurement program, 3 summer days are selected here for detailed analysis. Measurements on the third summer day (8 July) were interrupted by a very intense frontal activity with severe thunderstorm and huge amount of precipitation (including hails). Therefore, the previous two heat-wave days (6 and 7 July) are shown together with the warm day at the end of summer (28 August). The day-time temperature at the Ferenc square exceeded $30{ }^{\circ} \mathrm{C}$ on all the three days, the heat-wave days were certainly $3-4{ }^{\circ} \mathrm{C}$ warmer than the late August day. The maximum measured 


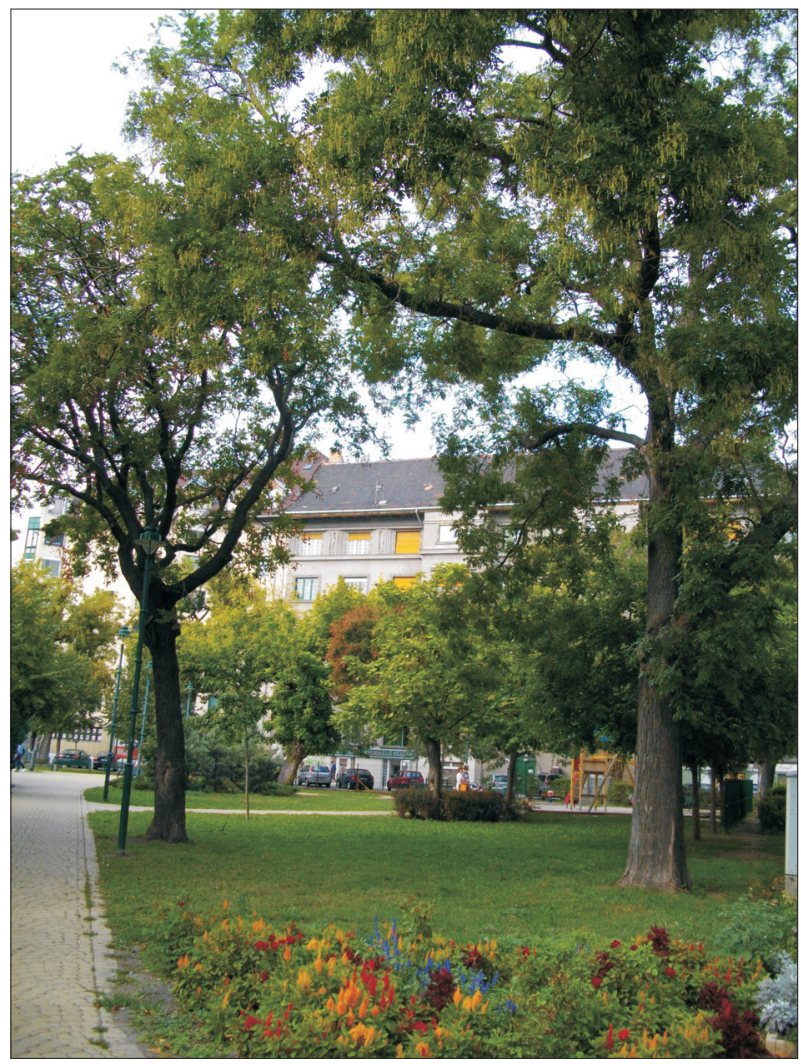

Photo 3. Measuring site with continuous recording at Ferenc square (site no. 105)

temperature values are as follows: $37.7^{\circ} \mathrm{C}$, $38.5^{\circ} \mathrm{C}$, and $35.8^{\circ} \mathrm{C}$ on 6 July, 7 July, and 28 August, respectively (Figure 7).

These warmest periods of the days were measured between 16:30 and 16:50. The overall daily courses of the temperature values are generally similar on the measuring days with the maximum between 16:00 and 17:00. After about 18:00 the measured temperature started to decrease. The temperature difference between the two sites decreased to $0.5-1.5{ }^{\circ} \mathrm{C}$ by the time before the sunset, which is probably due to the different speed of temperature change in the central and the outer city areas. Similar results were found for Poznań by PóŁrolniczak, M. et al. (2015). Then, after the sunset temperature difference started to increase again, whereas the meas- ured temperature continued to decrease. The temperature decrease was slower at Ferenc square, in the more densely built-up region of the city than at the suburban reference station resulting in higher UHI intensity values at the late evening.

The temperature difference between Ferenc square and the synoptic reference station was generally larger at the end of August compared to the heat-wave days in early July, which is partly due to the fact that during the heat-wave, all sites are very warm resulting in smaller overall differences.

In order to fully detect the UHI effect and characteristics longer (at least 4-5 hours longer) measurements would be necessary. We plan to extend the measuring period in the summer of 2016. 


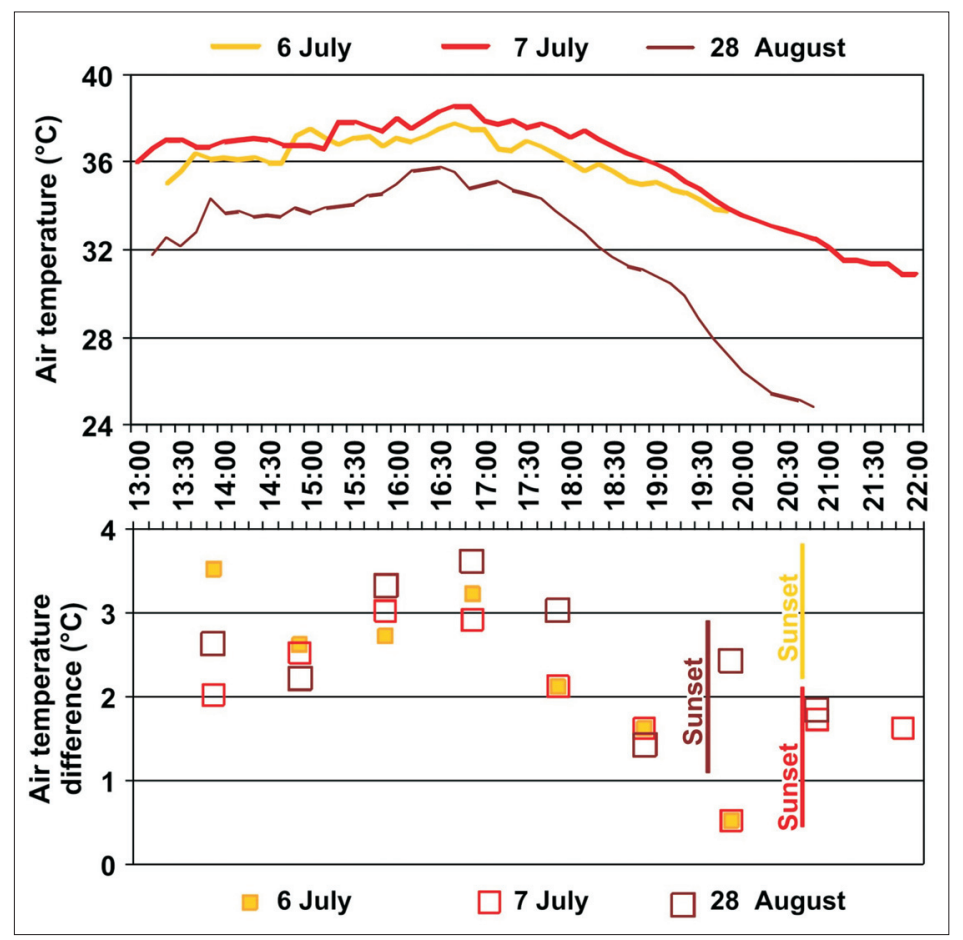

Fig. 7. Recorded air temperature at site no. 105 and the difference from the measurements at the BudapestPestszentlörinc synoptic station on the summer days in 2015. (Times of the sunset are indicated by vertical lines at 20:44, 20:44, and 19:34 on 6 July, 7 July, and 28 August, respectively.

\section{Conclusions}

A new in situ measurement program has been initiated at the Department of Meteorology of the Eötvös Loránd University. This program has been designed to extend our previous research focus from satellite-based measurements. As a first step we concentrate on a smaller area of the Ferencváros district in Budapest. Since March 2015 air temperature and relative humidity measurements have been regularly recorded along a multi-site path consisting of 22 measuring sites, and at a single measuring site in a representative vegetation covered square within the block rehabilitation zone and the Inner Ferencváros. The measurements available altogether from 20 days (spring, summer and autumn 2015) have been compared to the standard meteorological data from the synoptic station no. 12843 (Budapest-Pestszentlörinc located at the south-eastern part of the city). Our preliminary results highlight the general characteristics of the UHI effect.

The measurement program has just started, and we are planning to continue throughout 2016 and beyond in order to build year-round datasets for analyzing the seasonal cycle of temperature and relative humidity differences as well, as the diurnal changes and the spatial structure within the study area.

Acknowledgements: The measurements were carried out by involving MSc and BSc students at the Department of Meteorology. Research leading to this paper has been supported by the following sources: Hungarian Scientific Research Fund under grants K-78125, K-83909, K109109, the AGRÁRKLIMA2 project (VKSZ_12-1-2013-0034), and the Bolyai János Fellowship of the Hungarian Academy of Sciences. 


\section{REFERENCES}

Ben-Dor, E. and SAAroni, H. 1997. Airborne video thermal radiometry as a tool for monitoring microscale scructures of the urban heat island. International Journal of Remote Sensing 18. 3039-3053.

Budapest Capital Local Government 2011. Urban development strategy of Budapest. Budapest, 287 p. (in Hungarian).

Dezsô, Zs., Bartholy, J. and Pongrácz, R. 2005. Satellite-based analysis of the urban heat island effect. Idöjárás - Quarterly Journal of the Hungarian Meteorological Service 109. 217-232.

KSH 2012. STADAT Database. Central Statistical Office, Budapest. http://www.ksh.hu/stadat

Local Government of Ferencváros 2010. Rehabilitation of Budapest Ferencváros. Budapest. 80 p.

Оке, T.R. 1973. City size and the urban heat island. Atmospheric Environment 7. 769-779.

OKE, T.R. 1982. The energetic basis of the urban heat island. Quarterly Journal of the Royal Meteorological Society 108. 1-24.

PóŁrolniczak, M., Kolendowicz, L., Majkowska, A. and Czernecki, B. 2015. The influence of atmospheric circulation on the intensity of urban heat island and urban cold island in Poznań, Poland. Theoretical and Applied Climatology, DOI: 10.1007/ s00704-015-1654-0
Pongrácz, R., Bartholy, J. and Dezsó, Zs. 2006. Remotely sensed thermal information applied to urban climate analysis. Advances in Space Research 37. 2191-2196.

Pongrácz, R., Bartholy, J. and Dezső, Zs. 2010. Application of remotely sensed thermal information to urban climatology of Central European cities. Physics and Chemistry of the Earth 35. 95-99.

Pongrácz, R., Bartholy, J., Dezső, Zs. and Dian, Cs. 2015. Analysing the climatic effects of local block rehabilitation programs in Budapest-Ferencváros. Proceedings of the $9^{\text {th }}$ International Conference on Urban Climate (ICUC9), Toulouse, France. 20-24 July 2015. Extended abstract, $6 \mathrm{p}$.

PRICE, J.C. 1979. Assessment of the heat island effect through the use of satellite data. Monthly Weather Review 107. 1554-1557.

Unger, J., BotTyán, Zs., Sümeghy, Z. and Gulyás, Á. 2000. Urban heat island development affected by urban surface factors. Időjárás - Quarterly Journal of the Hungarian Meteorological Service 104. 253-268.

United Nations 2012. World Urbanization Prospects: The 2011 Revision. United Nations Population Division, Department of Economic and Social Affairs, http:// esa.un.org/unup/index.html 


\title{
Minsk and Budapest, the two capital cities
}

\author{
Edited by
}

\author{
LÁszló Jeney and Dávid Karácsonyi
}

\begin{abstract}
Department of Economic Geography and Futures Studies, Corvinus University of Budapest; Geographical Institute RCAES MTA; Faculty of Geography, Belarusian State University; Institute for Nature Management, National Academy of Sciences of Belarus
\end{abstract}

Budapest, 2015. 194 p.

While Budapest used to be the bridge between the West and East in Central Europe, Minsk seems to be in a similar role between the Russian and the EU-Polish influence zones. It means that both capitals are situated on the frontiers between the Euro-Atlantic and the Euro-Asian macro regions. Besides their situations, their similarity in size renders the comparison and the cooperation obvious to proceed. This book is based on the mutual

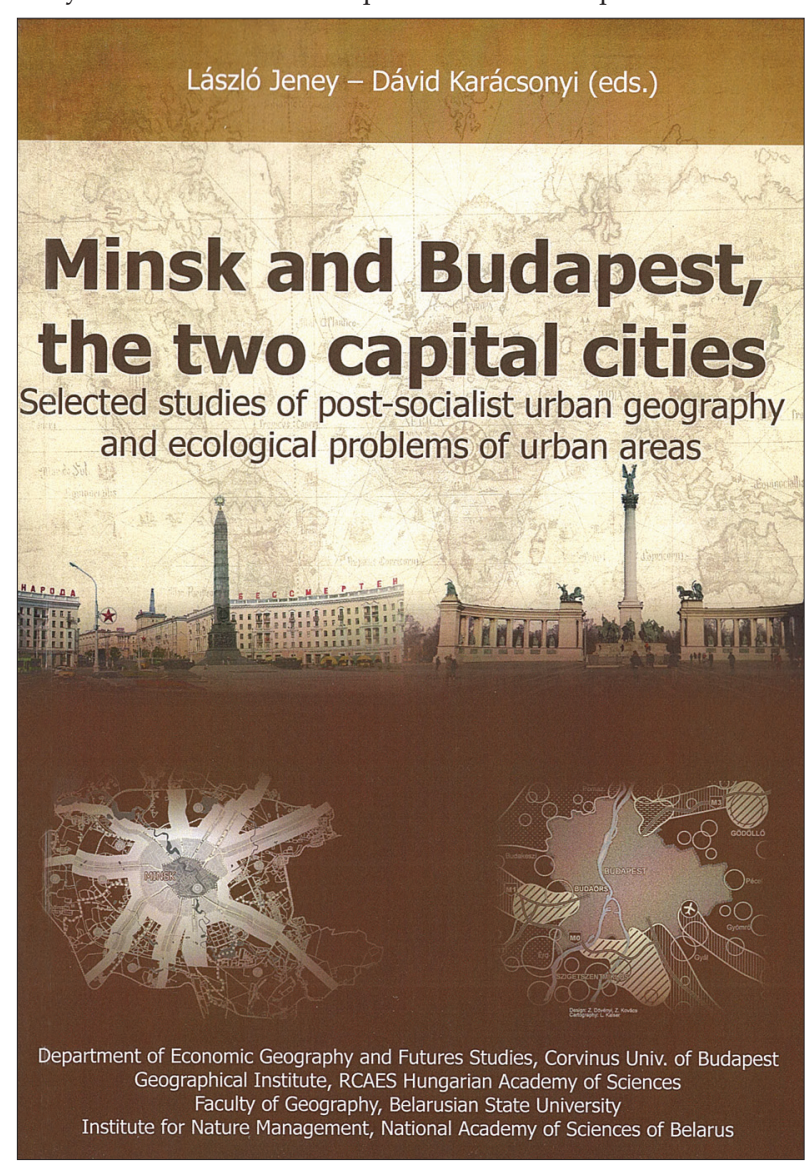

co-operation of Hungarian and Belarussian geographers and gives a scientific outlook not only on the socio-economic development of the two cities but on the urban climate, environment and ecology as well. Hungarian authors of the book introduce Budapest as a Central European metropolis with its historical trajectories and the results of the post-socialist transformation. They also demonstrate the main features of large housing estates and the results of their rehabilitation. Authors from Belarus show the major issues of spatial structure planning of Minsk in a similar context, describing the past and the present changes taking place in the spatial structure of the metropolis. The integrated assessment of the state of urban environment in Minsk is examined also focusing on the ecological frame of the environmental planning in urban agglomerations. The volume serves as a good starting point of a fruitful co-operation between Belarussian and Hungarian geographers dealing with a social and physical urban environment, the state of which deserves extra attention especially in East Central and Eastern Europe.

Copies are available:

Library, Geographical Institute of RCAES MTA, H-1112 Budapest, Budaörsi u. 44. E-mail: magyar.arpad@csfk.mta.hu 